\title{
Monitoring Methyl Benzimidazole Carbamate-Resistant Isolates of the Cucurbit Powdery Mildew Pathogen, Podosphaera xanthii, Using Loop-Mediated Isothermal Amplification
}

\author{
Alejandra Vielba-Fernández, Antonio de Vicente, Alejandro Pérez-García, and Dolores Fernández-Ortuño ${ }^{\dagger}$ \\ Departamento de Microbiología, Facultad de Ciencias, Universidad de Málaga, 29071 Málaga, Spain; and Departamento de \\ Microbiología, Instituto de Hortofruticultura Subtropical y Mediterránea, "La Mayora” Universidad de Málaga-Consejo Superior \\ de Investigaciones Científicas, Campus de Teatinos, 29071 Málaga, Spain
}

\begin{abstract}
Powdery mildew, caused by the fungus Podosphaera xanthii, is one of the most economically important diseases affecting cucurbit crops in Spain. Currently, chemical control offers the most efficient management of the disease; however, P. xanthii isolates resistant to multiple classes of site-specific fungicides have been reported in the Spanish cucurbit powdery mildew population. In previous studies, resistance to the fungicides known as methyl benzimidazole carbamates (MBCs) was found to be caused by the amino acid substitution E198A on $\beta$-tubulin. To detect MBC-resistant isolates in a faster, more efficient, and more specific way than the traditional methods used to date, a loop-mediated isothermal amplification (LAMP) system was developed. In this study, three sets of LAMP primers were designed. One set was designed for the detection of the wild-type allele and two sets were designed for the E198A amino acid change. Positive results were only obtained with both

mutant sets; however, LAMP reaction conditions were only optimized with primer set 2, which was selected for optimal detection of the E198A amino acid change in P. xanthii-resistant isolates, along with the optimal temperature and duration parameters of $65^{\circ} \mathrm{C}$ for $75 \mathrm{~min}$, respectively. The hydroxynaphthol blue (HNB) metal indicator was used for quick visualization of results through the color change from violet to sky blue when the amplification was positive. HNB was added before the amplification to avoid opening the lids, thus decreasing the probability of contamination. To confirm that the amplified product corresponded to the $\beta$-tubulin gene, the LAMP product was digested with the enzyme LweI and sequenced. Our results show that the LAMP technique is a specific and reproducible method that could be used for monitoring MBC resistance of $P$. xanthii directly in the field.
\end{abstract}

Powdery mildew diseases are major phytosanitary problems. Important crops, including cereals, grapevine, and a number of vegetable and ornamental plants, are among the major hosts of powdery mildew (Agrios 2005). Numerous vegetable crops are susceptible to powdery mildew, but cucurbits are arguably the group most severely affected (Pérez-García et al. 2009). Cucurbits are a very important crop worldwide and are especially important for Spanish agriculture. In Spain, within the strategic vegetable sector, cucurbit production is second only to tomato production, with an annual production of 2.9 million tons and value of $€ 1.1$ billion (Ministerio de Agricultura y Pesca y Alimentación 2015). Cucurbit powdery mildew symptoms appear a few days after the infection begins as white, powdery spots formed on both leaf surfaces, petioles, and stems and rarely on fruits (Sitterly 1978). In southern Spain, the disease is caused by Podosphaera xanthii, an obligate biotrophic ectoparasite responsible for significant yield losses affecting the quality and quantity of cucurbit crops under field and greenhouse conditions (Pérez-García et al. 2009). Crop yield may be reduced by up to $50 \%$, but in more extreme cases can cause complete yield loss (Leonar and Gianessi 2005).

${ }^{\dagger}$ Corresponding author: D. Fernández-Ortuño; dfernandez-ortuno@uma.es

Funding: This study was supported by the Agencia Estatal de Investigación and funds from project AGL2016-76216-C2-1-R (MINECO, Ministerio de Economía y Competitividad). A. Vielba-Fernández has received funds from the Ministerio de Ciencia, Innovación y Universidades (ayudas para la formación de profesorado universitario FPU17/00583). D. Fernández-Ortuño has received funds from the Ministerio de Economía, Industria y Competitividad Programa Ramón y Cajal (contrato RyC-2016-20776).

The author(s) declare no conflict of interest.

Accepted for publication 12 March 2019.

(c) 2019 The American Phytopathological Society
Fungicide applications and the use of resistant cultivars are the main means of disease control (Pérez-García et al. 2009). Unfortunately, the diversity of races of the pathogen hinders disease management through resistance breeding, and fungicides have played a decisive role in the management of this disease to date (McGrath 2001). However, the intense use of fungicides often results in the development of resistance involving a reduction in the control of the disease (Hollomon and Wheeler 2002). The cucurbit powdery mildew fungus has exhibited a high potential for developing resistance in many areas of the world to several fungicide classes (Ishii et al. 2001; McGrath 2001; Rur et al. 2018; Sedláková and Lebeda 2008). In Spain, different studies have reported very high levels of resistance to quinone outside inhibitors (QoIs; Fernández-Ortuño et al. 2006), sterol demethylation inhibitors (López-Ruiz et al. 2010), and methyl benzimidazole carbamates (MBCs) (Bellón-Gómez et al. 2015) in P. xanthii.

MBCs were first introduced in the 1960s for the control of many plant diseases, including gray mold, leaf blight, leaf scorch, leaf spot, and powdery mildew. MBCs possess unique properties (low use rates, broad-spectrum and systemic activity) that made them very popular with growers; however, resistance to the MBC benomyl has been described in cucurbit powdery mildew isolates from an experimental glasshouse in the United States in 1967 (Schroeder and Provvidenti 1969). MBC fungicides inhibit the production of microtubules by binding to the $\beta$-tubulin protein. One major reason for the extensive MBC-resistant populations in many fungal species worldwide is the mechanism of resistance based on point mutations in the gene encoding $\beta$-tubulin. Several target site mutations have been described in field isolates of many fungal species (Fernández-Ortuño et al. 2015; Ma and Michailides 2005) including the amino acid substitution E198A in P. xanthii (Vela-Corcía et al. 2014). In addition, positive cross-resistance between the two MBC chemical groups (benzimidazoles and thiophanates) has also been reported (Fungicide Resistance Action Committee 2019).

To maintain healthy crops and reliable, high-quality yields, there is a pressing demand to identify and develop new crop protection tools. 
In many diagnostic situations, the time required to obtained results is fundamental because an information-based, short-term decision has to be made. Powdery mildews are comparatively difficult fungi to work with because of their biotrophic nature and inability to grow on artificial culture medium. Monitoring for fungicide resistance in the field via current sensitivity assays takes weeks (FernándezOrtuño et al. 2006). For this reason, molecular assays have gained increasing importance in the diagnosis of mutations in target genes involved in fungicide resistance problems. These assays have been mainly based on the concept of polymerase chain reaction (PCR), such as PCR amplification and direct sequencing of the target gene in sensitive and resistant isolates (Fernández-Ortuño et al. 2008), allele-specific PCR (Ma and Michailides 2004), restriction fragment length polymorphism analysis after PCR amplification of the target gene (Ma et al. 2005), or primer-introduced restriction analysis (Luo et al. 2009). DNA amplification using isothermal conditions has gained increasing attention because these reactions can be run with less effort and expense compared with PCR and provide quick and reliable results (Niessen 2014).

Loop-mediated isothermal amplification (LAMP) is a gene amplification technique that amplifies nucleic acids with high efficiency, rapidity, sensitivity, and specificity under isothermal conditions by using a DNA polymerase with strand displacement activity and a set of primers composed of two inner primers, the forward inner primer (FIP; F1c+F2) and the backward inner primer (BIP; B1c+ B2), and two outer primers (F3 and B3). This technique has been successfully used for the rapid detection of several plant pathogens (Niessen 2014) and point mutations that confer resistance to QoIs (Hu et al. 2017), succinate-dehydrogenase inhibitors (Fan et al. 2018), and especially MBC fungicides (Duan et al. 2014, 2015, 2016a, 2016b, 2018a, 2018b).
In this study, we intended to use LAMP technology as a rapid and reliable approach for the detection of the E198A mutant genotype of MBC-resistant isolates in P. xanthii as part of a fungicide resistancemonitoring program in the field. Our findings will help growers prevent the application of ineffective fungicides and improve current resistance management strategies for the cucurbit powdery mildew pathogen.

\section{Materials and Methods}

Fungal isolates and culture conditions. A total of $68 P$. xanthii single-spore isolates were analyzed in this study. Forty-nine isolates were collected from infected cucurbit samples (cucumber, melon, pumpkin, watermelon, and zucchini) from several geographical areas (Almería, Córdoba, Granada, Málaga, Murcia, and Valencia) in Spain from 1988 to 2018. In addition, 19 P. xanthii monoconidial isolates collected from cucurbit-infected material in other countries (Austria, France, Greece, and Italy) were also included. The isolates were kept at $-80^{\circ} \mathrm{C}$ until use as previously described (Pérez-García et al. 2006). For conidia production, all isolates were cultured on zucchini cultivar Negro Belleza (Cucurbita pepo L.; Semillas Fitó) and maintained in vitro as previously described (Álvarez and Torés 1997). To confirm the specificity of the LAMP assay, other phytopathogenic fungi, such as Aspergillus niger, Botrytis cinerea, Didymella bryoniae, Fusarium oxysporum, Macrophomina phaseolina, and Penicillium digitatum, were also tested. These isolates were collected from different hosts or locations in Spain and were cultured on potato dextrose agar (VWR Chemicals) plates at $25^{\circ} \mathrm{C}$ in the dark for maintenance.

DNA extraction. For genomic DNA extraction, the biomass of $P$. xanthii isolates was carefully harvested from heavily powdery mildew-infected zucchini cotyledons. Total DNA was extracted

\section{$\beta$-tubulin gen}

3260 bp 3465 bp

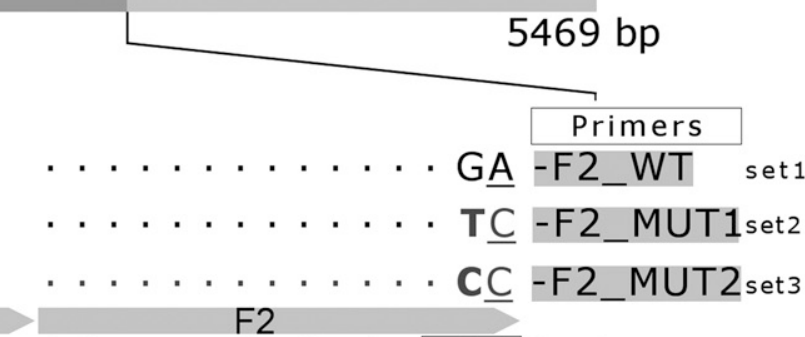

WT- 5 ' -...ACTCTCTGTC CACCAGCTAGTCGAAAACTCTGATGAGAC MUTANT- 5 ' - ... ACTCTCTGTC CACCAGCTAGTCGAAAACTCTGATG

WT- TTTTTGCATCGACAATGAGGCACTTTATGACATTTGTATGAGG MUTANT- TTTTTGCATCGACAATGAGGCACTTTATGACATTTGTATGAGG

WT- ACATTGAAGCTTAACAACCCTTCATATGGCGACCTCAATCACC MUTANT- ACATTGAAGCTTAACAACCCTTCATATGGCGACCTCAATCACC

WT- TGGTTTCTGCTGTCATGTCTGGTGTGACCACATGTCTACGGTT MUTANT- TGGTTTCTGCTGTCATGTCTGGTGTGACCACATGTCTACGGTT

WT- TCCTGGTCAGCTAAACTCCGATCTACGAAAGTTGGCTGT...-3' MUTANT- TCCTGGTCAGCTAAACTCCGATCTACGAAAGTTGGCTGT...-3'

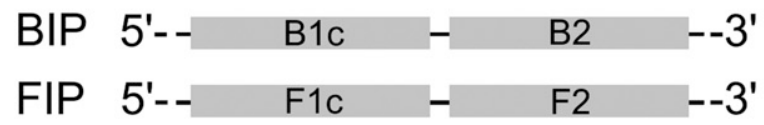

Fig. 1. Schematic representation of loop-mediated isothermal amplification primers in the $\beta$-tubulin gene to detect the E198A mutant genotype in Podosphaera xanthii. WT = wild type, MUT = mutant, BIP = backward inner primer, and FIP = forward inner primer. 
using the MasterPure Yeast DNA Purification Kit (Epicentre) following the manufacturer's recommendations for fungal tissues. For the rest of the fungal species, genomic DNA was extracted as previously described by Chi et al. (2009). Briefly, 10 to $20 \mathrm{mg}$ of fungal mycelia was picked with a pipette tip and placed into a 1.5-ml Eppendorf tube containing $0.5 \mathrm{ml}$ of extraction buffer (1 M KCl [Sigma], $100 \mathrm{mM}$ Tris- $\mathrm{HCl}$ [Roche], $10 \mathrm{mM}$ EDTA [Fluka]). After pulverization of the fungal mass with an electric grinder and centrifugation at $5,000 \mathrm{rpm}$ for $10 \mathrm{~min}$, the supernatant was decanted into $1.5-\mathrm{ml}$ tubes containing 2-propanol (Prolabo). Then centrifugation at 12,000 rpm for $10 \mathrm{~min}$ was carried out, and the supernatant was decanted. Finally, the DNA pellet was dissolved in $50 \mu l$ of distilled water and stored at $-20^{\circ} \mathrm{C}$ until use.

LAMP primers. Three sets of LAMP primers were designed based on the amino acid substitution E198A linked with $\beta$-tubulin in P. xanthii (Fig. 1; Table 1). Primer Explorer software version 5 (http://primerexplorer.jp/e/) was used following the manufacturer's instructions. The FIP was composed of the complementary sequence of F1 (F1c) and F2. The BIP consisted of the complementary sequence of B1 (B1c) and B2. Finally, the outer primers F3 and B3 were designed to initiate the LAMP reaction. Mismatched bases were introduced at the $3^{\prime}$ end of two FIP primers to separate E198A genotype isolates from sensitive ones (Table 1).

Reaction mixture for LAMP. Optimization of the LAMP primers was performed using genomic DNA from the $P$. xanthii wild-type (WT) isolate SF26 and the mutant isolate 2237, previously characterized for their sensitivity to thiophanate-methyl (Topsin 70WG, Bayer CropScience, S.L.) and for carrying a glutamic acid (E) or alanine (A) at position 198, respectively. LAMP reactions were carried out in a digital dry bath (Labnet International Inc.) using the optimal LAMP reaction components and conditions described by the manufacturer's recommendations for Bst 2.0 WarmStart DNA polymerase (New England Biolabs). The reaction was performed in PCR tubes with a final volume of $10 \mu \mathrm{l}$ containing 3.2 U of Bst 2.0 WarmStart DNA polymerase, $1 \mu l$ of $10 \times$ Isothermal Amplification Buffer (New England Biolabs), $6 \mathrm{mM}$ of $\mathrm{MgSO}_{4}$ (New England Biolabs), $1 \mathrm{mM}$ of deoxynucleotide triphosphates (dNTPs) (Invitrogen), 1.6 $\mu \mathrm{M}$ each of FIP and BIP, $0.2 \mu \mathrm{M}$ each of F3 and B3, 0.8 M of betaine (Sigma), and $20 \mathrm{ng}$ of the fungal DNA template. LAMP amplification was achieved at $65^{\circ} \mathrm{C}$ for $60 \mathrm{~min}$. The LAMP products were separated in RedSafe-stained (INtRON Biotechnology) $2 \%$ agarose gels (Thermo Scientific), run in $1 \times$ Tris-borate-EDTA buffer, and exposed to ultraviolet (UV) light to visualize the products. In addition, positive LAMP reactions were visually determined based on the color change from violet to sky blue after the addition of $120 \mu \mathrm{M}$ of hydroxynaphthol blue (HNB; Fluka). This experiment was repeated at least three times.

Optimization of temperature and time for LAMP reactions. When the optimal LAMP primers were selected, temperature $\left(63^{\circ} \mathrm{C}, 64^{\circ} \mathrm{C}, 65^{\circ} \mathrm{C}, 66^{\circ} \mathrm{C}, 67^{\circ} \mathrm{C}\right.$, and $\left.68^{\circ} \mathrm{C}\right)$ and time $(15,30,45$, 60,75 , and $90 \mathrm{~min}$ ) parameters were optimized for LAMP reactions using genomic DNA from the $P$. xanthii isolates SF26 (WT) and 2237 (E198A-mutant) as templates. The amplification products were

Table 1. Sequence and description of the primers used in this study

\begin{tabular}{|c|c|c|}
\hline Primer name $^{a}$ & Sequence $\left(5^{\prime}-3^{\prime}\right)^{b}$ & Description \\
\hline $\begin{array}{l}\text { TubFw } \\
\text { TubRv }\end{array}$ & $\begin{array}{l}\text { CGCTGAAAAGGCCTCTGGTA } \\
\text { CAATCGGGGAAATGGGACCA }\end{array}$ & $\begin{array}{l}\text { Used to amplify a 640-bp fragment of the } \\
\beta \text {-tubulin gene of Podosphaera xanthii }\end{array}$ \\
\hline \multicolumn{3}{|l|}{ LAMP primer } \\
\hline F3 & CTCTGTCCACCAGCTAGT & Forward outer primer \\
\hline B3 & AACTTTCGTAGATCGGAGTT & Backward outer primer \\
\hline $\mathrm{F} 2$ & CGAAAACTCTGATGA & \\
\hline $\mathrm{B} 2$ & CTGACCAGGAAACCGTAG & \\
\hline F1c & GAAGGGTTGTTAAGCTTCAATGT & \\
\hline B1c & GCGACCTCAATCACCTGGT & \\
\hline BIP & GCGACCTCAATCACCTGGTCTGACCAGGAAACCGTAG & Backward inner primer \\
\hline FIPWT & GAAGGGTTGTTAAGCTTCAATGTCGAAAACTCTGATGA & \multirow{3}{*}{$\begin{array}{l}3 \text { different sets of the forward inner primer } \\
\text { used to identify the E198A mutation }\end{array}$} \\
\hline FIPMUT1 & GAAGGGTTGTTAAGCTTCAATGTCGAAAACTCTGATTC̄ & \\
\hline FIPMUT2 & GAAGGGTTGTTAAGCTTCAATGTCGAAAACTCTGATCㅡㅡ & \\
\hline
\end{tabular}

Table 2. Fungal isolates used for loop-mediated isothermal amplification (LAMP) specificity

\begin{tabular}{|c|c|c|c|c|c|c|c|}
\hline Isolate & Fungal species & Host & Year & Origin & Phenotype & Genotype & $\operatorname{LAMP}(+/-)^{\mathbf{a}}$ \\
\hline SF9 & Podosphaera xanthii & Zucchini & 1988 & Málaga & Sensitive & E198 & - \\
\hline SF26 & P. xanthii & Melon & 1989 & Málaga & Sensitive & E198 & - \\
\hline SF56 & P. xanthii & Melon & 1999 & Almería & Sensitive & E198 & - \\
\hline 2237 & P. xanthii & Zucchini & 2002 & Almería & Resistant & A198 & + \\
\hline 24794 & P. xanthii & Watermelon & 2004 & Almería & Resistant & A198 & + \\
\hline 61485 & P. xanthii & Melon & 2003 & Córdoba & Resistant & A198 & + \\
\hline An & Aspergillus niger & Onion & 2017 & Málaga & Unknown & Unknown & - \\
\hline 155 & Botrytis cinerea & Strawberry & 2014 & Huelva & Sensitive & E198 & - \\
\hline 229 & B. cinerea & Strawberry & 2014 & Huelva & Sensitive & E198 & - \\
\hline 290 & B. cinerea & Strawberry & 2015 & Huelva & Resistant & A198 & - \\
\hline Did & Didymella bryoniae & Pumpkin & 2016 & Valencia & Unknown & Unknown & - \\
\hline Fo & Fusarium oxysporum & Unknown & 2017 & Málaga & Unknown & Unknown & - \\
\hline Mac & Macrophomina phaseolina & Strawberry & 2006 & Huelva & Unknown & Unknown & - \\
\hline $\mathrm{Pd}$ & Penicillium digitatum & Orange & 2017 & Málaga & Unknown & F200 & - \\
\hline
\end{tabular}

a Plus signs indicate a sky-blue color of hydroxynaphthol blue (HNB) and a ladder-like pattern was displayed on the electrophoretic gel. Minus signs indicate a violet color of HNB and a lack of pattern-like banding on gel electrophoresis. 
visualized using gel electrophoresis and HNB as described previously. The assay was performed three times.

Confirmation of the LAMP products. To investigate whether the LAMP products correspond with a fragment of the $\beta$-tubulin gene and the nucleotide alteration E198A in P. xanthii, the restriction enzyme LweI (SfaNI) (Thermo Fisher Scientific) was used. LAMP reactions and conventional PCR were carried out using genomic DNA from one MBC-sensitive (SF26) and an MBC-resistant (2237) $P$. xanthii isolate. LAMP reactions were performed using the optimized primers and conditions described previously, and positive reactions were confirmed with HNB color change. PCRs were accomplished using the LAMP primers F3 and B3 (Table 1). PCRs were performed in a final volume of $50 \mu \mathrm{l}$ containing $20 \mathrm{ng}$ of fungal genomic DNA, $0.2 \mathrm{mM}$ of dNTPs, $0.2 \mu \mathrm{M}$ of each primer, $10 \mu \mathrm{l}$ of
$5 \times$ Green GoTaq Flexi Buffer (Promega), $4 \mathrm{mM}$ of $\mathrm{MgSO}_{4}$, and $1.25 \mathrm{U}$ of GoTaq Flexi DNA polymerase (Promega). PCR amplifications were achieved in a MyCycler thermal cycler (Bio-Rad Laboratories) as follows: an initial preheating at $95^{\circ} \mathrm{C}$ for $3 \mathrm{~min}$, followed by 35 cycles consisting of $30 \mathrm{~s}$ of denaturation at $95^{\circ} \mathrm{C}, 30 \mathrm{~s}$ of annealing at $50^{\circ} \mathrm{C}$, and $12 \mathrm{~s}$ of extension at $72^{\circ} \mathrm{C}$, with a final extension stage of 4 min at $72^{\circ} \mathrm{C}$. The LAMP product was reamplified by PCR using the primers $\mathrm{F} 3$ and $\mathrm{B} 3$ at the same conditions described before. Aliquots of $10 \mu \mathrm{l}$ of the PCR and the reamplified LAMP products were separated on $1 \%$ agarose gels stained with RedSafe nucleic acid, run in $1 \times$ Tris-borate-EDTA buffer, and exposed to UV light to visualize the 198-bp amplification product. Both products were purified using the Illustra GFX PCR DNA and Gel Band Purification Kit (GE Healthcare) according to the manufacturer's instructions. Then

Table 3. Sensitive phenotype, positive and negative loop-mediated isothermal amplification (LAMP) results, and presence or absence of the point mutation E198A in the $\beta$-tubulin gene of Podosphaera xanthii isolates collected from different countries

\begin{tabular}{|c|c|c|c|c|c|c|}
\hline Origin & Isolate & Host & Year & Phenotype $^{\mathrm{a}}$ & $\operatorname{LAMP}(+/-)^{\mathbf{b}}$ & E198A mutation ${ }^{c}$ \\
\hline \multicolumn{7}{|l|}{$\overline{\text { Austria }}$} \\
\hline \multirow{5}{*}{ Korneuburg } & $18090501 \mathrm{~A}$ & Pumpkin & 2018 & Sensitive & - & Not determined \\
\hline & 18090501B & Pumpkin & 2018 & Sensitive & - & Not determined \\
\hline & $18090501 \mathrm{C}$ & Pumpkin & 2018 & Sensitive & - & Not determined \\
\hline & 18090501D & Pumpkin & 2018 & Sensitive & - & Not determined \\
\hline & $18090501 \mathrm{E}$ & Pumpkin & 2018 & Resistant & + & Not determined \\
\hline Rohrau & $18090502 \mathrm{~A}$ & Pumpkin & 2018 & Sensitive & - & Not determined \\
\hline \multicolumn{7}{|l|}{ France } \\
\hline \multirow[t]{4}{*}{ Gard } & $18090504 \mathrm{~A}$ & Pumpkin & 2018 & Sensitive & - & Not determined \\
\hline & 18090504B & Pumpkin & 2018 & Sensitive & - & Not determined \\
\hline & $18090504 \mathrm{C}$ & Pumpkin & 2018 & Sensitive & - & Not determined \\
\hline & 18090504D & Pumpkin & 2018 & Sensitive & - & Not determined \\
\hline \multicolumn{7}{|l|}{ Greece } \\
\hline Unknown & 2086 & Melon & 1997 & Sensitive & - & Absent \\
\hline Unknown & SF61 & Cucumber & 1999 & Sensitive & - & Absent \\
\hline \multicolumn{7}{|l|}{ Italy } \\
\hline \multirow[t]{7}{*}{ Lazio } & $18090203 \mathrm{~A}$ & Zucchini & 2018 & Sensitive & - & Not determined \\
\hline & $18090203 \mathrm{~B}$ & Zucchini & 2018 & Resistant & + & Not determined \\
\hline & $18090203 \mathrm{C}$ & Zucchini & 2018 & Resistant & + & Not determined \\
\hline & $18090203 \mathrm{D}$ & Zucchini & 2018 & Resistant & + & Not determined \\
\hline & $18090203 \mathrm{E}$ & Zucchini & 2018 & Resistant & + & Not determined \\
\hline & $18090203 \mathrm{~F}$ & Zucchini & 2018 & Resistant & + & Not determined \\
\hline & $18090203 \mathrm{G}$ & Zucchini & 2018 & Resistant & + & Not determined \\
\hline \multicolumn{7}{|l|}{ Spain } \\
\hline \multirow[t]{7}{*}{ Almería } & 2208 & Zucchini & 2002 & Resistant & + & Present \\
\hline & 2214 & Zucchini & 2002 & Resistant & + & Present \\
\hline & 22304 & Zucchini & 2003 & Resistant & + & Present \\
\hline & 22317 & Zucchini & 2003 & Resistant & + & Present \\
\hline & $1502404 \mathrm{~A}$ & Watermelon & 2015 & Resistant & + & Present \\
\hline & $18020303 \mathrm{M}$ & Cucumber & 2018 & Resistant & + & Present \\
\hline & $18020303 \mathrm{P}$ & Cucumber & 2018 & Resistant & + & Present \\
\hline Córdoba & 61140 & Melon & 2002 & Resistant & + & Present \\
\hline \multirow[t]{2}{*}{ Granada } & $18130302 \mathrm{~J}$ & Cucumber & 2018 & Resistant & + & Present \\
\hline & $18130302 \mathrm{~L}$ & Cucumber & 2018 & Resistant & + & Present \\
\hline Málaga & SF8 & Melon & 1988 & Sensitive & - & Absent \\
\hline \multirow[t]{11}{*}{ Murcia } & 31464 & Zucchini & 2003 & Resistant & + & Present \\
\hline & 3190 & Melon & 2002 & Resistant & + & Present \\
\hline & $18030306 \mathrm{~A}$ & Cucumber & 2018 & Resistant & + & Not determined \\
\hline & $18030306 \mathrm{~B}$ & Cucumber & 2018 & Resistant & + & Not determined \\
\hline & $18030306 \mathrm{C}$ & Cucumber & 2018 & Resistant & + & Not determined \\
\hline & $18030306 \mathrm{D}$ & Cucumber & 2018 & Resistant & + & Not determined \\
\hline & $18030306 \mathrm{E}$ & Cucumber & 2018 & Resistant & + & Not determined \\
\hline & $18030306 \mathrm{~F}$ & Cucumber & 2018 & Resistant & + & Not determined \\
\hline & $18030306 \mathrm{G}$ & Cucumber & 2018 & Resistant & + & Not determined \\
\hline & $18030306 \mathrm{H}$ & Cucumber & 2018 & Resistant & + & Not determined \\
\hline & 18030306I & Cucumber & 2018 & Resistant & + & Not determined \\
\hline Valencia & 45631 & Pumpkin & 2003 & Resistant & + & Present \\
\hline
\end{tabular}

a Thiophanate-methyl was tested at the discriminatory dose of $675 \mu \mathrm{g} / \mathrm{ml}$; only the resistant isolates were able to grow on the treated leaf discs.

${ }^{b}$ Plus signs indicate the hydroxynaphthol blue (HNB) color change from violet to sky blue and a ladder-like pattern was displayed on the gel electrophoresis. Minus signs indicate the sky-blue color of HNB and lack of pattern-like banding on the electrophoretic gel.

${ }^{\mathrm{c}}$ The $\beta$-tubulin gene was amplified with primers F3 and B3, and the amplification product was sequenced in both directions. 
$16.5 \mu \mathrm{l}$ of the purified products was digested at $37^{\circ} \mathrm{C}$ for $1.5 \mathrm{~h}$ and incubated at $65^{\circ} \mathrm{C}$ for $20 \mathrm{~min}$ for enzyme inactivation. Digested fragments were visualized by electrophoresis in $15 \%$ acrylamide (Roche) gels. The LAMP and PCR amplification products were also sequenced in both directions using the primers F3 and B3 at STAB VIDA (STAB VIDA Lda.). Sequences were analyzed using DNASTAR computer sequence analysis software (DNASTAR Inc.).

Specificity of LAMP primers to $\boldsymbol{P}$. xanthii. The specificity of LAMP was determined using genomic DNA from two previously characterized thiophanate-methyl-sensitive (SF9 and SF56) and two E198A-resistant (24794 and 61485) isolates together with six other fungal species: A. niger, B. cinerea, D. bryoniae, F. oxysporum, M. phaseolina, and Penicillium digitatum (Table 2). The reactions were performed using the optimal LAMP conditions. DNA from the mutant $P$. xanthii isolate 2237 was included as a positive control of the reaction (Table 2). Reactions with DNA from the WT isolate SF26 and without template DNA were also included as negative controls (Table 2). The experiment was performed three times.

Repeatability of LAMP using $P$. xanthii isolates from different countries. The reproducibility of the LAMP assay was achieved using 42 single-spore isolates collected from cucumberinfected material from Austria (six isolates), France (four isolates),
Greece (two isolates), Italy (seven isolates), and several locations in Spain, including Almería (seven isolates), Córdoba (one isolate), Granada (two isolates), Málaga (one isolate), Murcia (11 isolates), and Valencia (one isolate) (Table 3). A leaf-disc bioassay was also used to determine the MBC-sensitivity phenotypes of these $P$. xanthii isolates. A commercial formulation of the MBC fungicide thiophanate-methyl was used for the bioassay. To carry out the fungicide sensitivity test, the conditions and methods reported by Fernández-Ortuño et al. (2006) were used with minor modifications. Briefly, leaf discs obtained from 8-day-old zucchini cotyledons were treated with $3 \mathrm{ml}$ of fungicide solution in $9-\mathrm{cm}-$ diameter Petri dishes. The test was performed with a discriminatory dose of $675 \mu \mathrm{g} / \mathrm{ml}$ of thiophanate-methyl that was able to distinguish sensitive from resistant isolates (Bellón-Gómez et al. 2015). Untreated control discs were imbibed with $3 \mathrm{ml}$ of sterile water. After $1 \mathrm{~h}$, the discs were placed onto agarized medium and inoculated with conidia of the selected $P$. xanthii isolate using a soft paintbrush. After 8 to 10 days of incubation, powdery mildew symptoms were recorded (Fernández-Ortuño et al. 2006). For LAMP reactions, genomic DNA from the 42 single-spore $P$. xanthii isolates was used. The reactions were performed using the optimal reaction conditions. The results were visualized using gel

Table 4. Field samples tested with a discriminatory-dose leaf-disc bioassay and loop-mediated isothermal amplification (LAMP) for monitoring methyl benzimidazole carbamate resistance

\begin{tabular}{|c|c|c|c|c|c|}
\hline Isolate & Host & Year & Origin & Phenotype $^{\mathrm{a}}$ & $\operatorname{LAMP}(+/-)^{\mathbf{b}}$ \\
\hline \multicolumn{6}{|l|}{ Bulk conidial mass } \\
\hline 18130304M1.1 & Cucumber & 2018 & Granada & Sensitive & - \\
\hline 18130304M1.2 & & & & Sensitive & - \\
\hline $18130304 \mathrm{M} 1.3$ & & & & Sensitive & - \\
\hline 18130304M1.4 & & & & Sensitive & - \\
\hline $18130304 \mathrm{M} 2.1$ & Cucumber & 2018 & Granada & Resistant & + \\
\hline $18130304 \mathrm{M} 2.2$ & & & & Resistant & + \\
\hline $18130304 \mathrm{M} 2.3$ & & & & Resistant & + \\
\hline $18130304 \mathrm{M} 2.4$ & & & & Resistant & + \\
\hline $18130304 \mathrm{M} 3.1$ & Cucumber & 2018 & Granada & Sensitive & - \\
\hline $18130304 \mathrm{M} 3.2$ & & & & Sensitive & - \\
\hline $18130304 \mathrm{M} 3.3$ & & & & Sensitive & - \\
\hline $18130304 \mathrm{M} 3.4$ & & & & Sensitive & - \\
\hline \multicolumn{6}{|c|}{ Single-conidia isolate } \\
\hline $18130304 \mathrm{~A}$ & Cucumber & 2018 & Granada & Resistant & + \\
\hline 18130304B & & & & Sensitive & - \\
\hline 18130304D & & & & Sensitive & - \\
\hline $18130304 \mathrm{E}$ & & & & Resistant & + \\
\hline $18130304 \mathrm{~F}$ & & & & Sensitive & - \\
\hline $18130304 \mathrm{G}$ & & & & Sensitive & - \\
\hline 18130304I & & & & Resistant & + \\
\hline $18130304 \mathrm{~J}$ & & & & Resistant & + \\
\hline $18130304 \mathrm{M}$ & & & & Sensitive & - \\
\hline $18130304 \mathrm{O}$ & & & & Sensitive & - \\
\hline \multicolumn{6}{|l|}{ Bulk conidial mass } \\
\hline $18020305 \mathrm{M} 1.1$ & Cucumber & 2018 & Almería & Resistant & + \\
\hline $18020305 \mathrm{M} 1.2$ & & & & Resistant & + \\
\hline $18020305 \mathrm{M} 1.3$ & & & & Resistant & + \\
\hline $18020305 \mathrm{M} 1.4$ & & & & Resistant & + \\
\hline \multicolumn{6}{|c|}{ Single-conidia isolate } \\
\hline $18020305 \mathrm{~A}$ & Cucumber & 2018 & Almería & Resistant & + \\
\hline 18020305B & & & & Resistant & + \\
\hline $18020305 \mathrm{C}$ & & & & Resistant & + \\
\hline $18020305 \mathrm{D}$ & & & & Resistant & + \\
\hline $18020305 \mathrm{E}$ & & & & Resistant & + \\
\hline $18020305 \mathrm{~F}$ & & & & Resistant & + \\
\hline $18020305 \mathrm{G}$ & & & & Resistant & + \\
\hline $18020305 \mathrm{H}$ & & & & Resistant & + \\
\hline $18020305 \mathrm{~J}$ & & & & Resistant & + \\
\hline $18020305 \mathrm{~K}$ & & & & Resistant & + \\
\hline
\end{tabular}

a Thiophanate-methyl was tested at the discriminatory dose of $675 \mu \mathrm{g} / \mathrm{ml}$; only the resistant isolates were able to grow on the treated leaf discs.

b Plus signs indicate an HNB color change from violet to sky blue and a ladder-like pattern displayed via the gel electrophoresis. Minus signs indicate the sky-blue color of HNB and a lack of pattern-like banding on the electrophoretic gel. 
electrophoresis and HNB color change. To confirm the absence or presence of the E198A mutation, PCRs were also carried out using the forward and reverse primers TubFw and TubRv, respectively (Table 1), which amplify a 640-bp fragment of $\beta$-tubulin for some randomly chosen $P$. xanthii isolates. PCRs were carried out using the same components described previously but in this case, the PCR run parameters used were as follows: $2 \mathrm{~min}$ at $95^{\circ} \mathrm{C}$, followed by 40 cycles of $95^{\circ} \mathrm{C}$ for $1 \mathrm{~min}, 60^{\circ} \mathrm{C}$ for $1 \mathrm{~min}$, and $72^{\circ} \mathrm{C}$ for $40 \mathrm{~s}$, with a final elongation at $72^{\circ} \mathrm{C}$ for $5 \mathrm{~min}$. PCR products were purified and sequenced at STAB VIDA, and sequences were analyzed using DNASTAR software. DNA from P. xanthii isolates SF26 and 2237 was included as the negative and positive control of the reaction, respectively. All experiments were performed three times.

Application of LAMP for monitoring MBC-resistant field isolates of $\boldsymbol{P}$. xanthii. To verify the application of the LAMP assay for on-site MBC resistance detection, a total of four cucumber powdery mildew-infected materials collected from two locations in the southeast of Spain (three samples from Granada and one from Almería) were tested during 2018 (Table 4). For each infected plant material, an amount of fungal biomass $(\geq 400$ spores/ $\mu \mathrm{l})$ covering the lower end of a pipette tip was taken from four equidistant points with at least $10 \mathrm{~cm}$ between them and transferred into $0.2-\mathrm{ml}$ PCR tubes containing $10 \mu \mathrm{l}$ of sterile distilled water. The tubes were incubated at $95^{\circ} \mathrm{C}$ for $5 \mathrm{~min}$ in a digital dry bath, and the lysed supernatant was used as the DNA template. In addition, 20 single-spore isolates (10 from Granada and 10 from Almería; Table 4) were obtained from the cucumber-infected material tested above and maintained on zucchini cotyledons. After 3 weeks of incubation at $25^{\circ} \mathrm{C}$ with a $16-\mathrm{h} / 8-\mathrm{h}$ light/dark photoperiod, the lysed supernatant from each single-spore isolate was used as the DNA template as described previously. The LAMP assay was conducted using the optimal conditions, and the results were visualized by HNB color change and gel electrophoresis. A leaf-disc bioassay was also conducted to determine the MBCsensitivity phenotypes of these $P$. xanthii isolates. All experiments were repeated three times.

Sensitivity of LAMP compared with conventional PCR. Tenfold serially diluted genomic DNA extracted using the MasterPure Yeast DNA Purification Kit from the E198A mutant isolate 2237 and 10-fold serially diluted DNA obtained directly from the powdery mildew-infected material (bulk conidial mass 18020305M1.2; Table 4) were used as templates for LAMP and PCRs. For LAMP, the optimized primers and reaction conditions were used. For conventional PCR, the reactions were carried out using primers TubFw

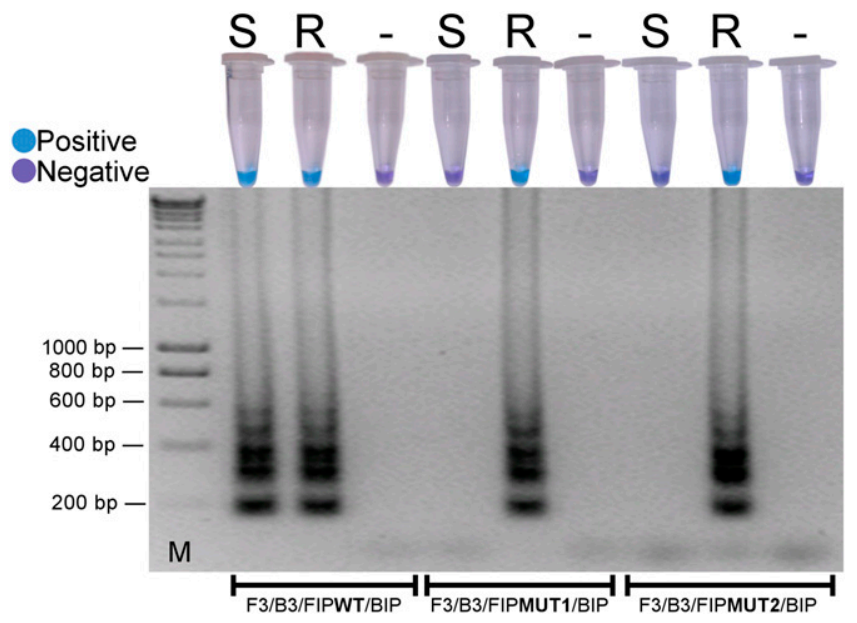

Fig. 2. Specificity of loop-mediated isothermal amplification (LAMP) using different primer sets. LAMP products were visualized by hydroxynaphthol blue color change and agarose gel electrophoresis. Dashes indicate the negative control without template DNA. $S=$ LAMP reaction performed using template DNA from the sensitive isolate SF26, $R=$ LAMP reaction carried out using DNA from the resistant isolate $2237, \mathrm{M}=$ hyperladder $1 \mathrm{~kb}$ (Bioline), FIP = forward inner primer, WT $=$ wild type, BIP = backward inner primer, and MUT = mutant. and TubRv and the conditions described for these primers above. In both cases, only $1 \mu \mathrm{l}$ of the corresponding DNA dilution was used as a template. LAMP and PCR amplifications were separated in RedSafe-stained $2 \%$ and $1 \%$ agarose gels, respectively. In addition, negative and positive LAMP reactions were visualized by HNB color change. The detection limit was represented by the lowest DNA concentration at which positive results were detected. The assay was performed three times.

\section{Results}

Selection of primers and optimization of temperature and time for LAMP reactions. To distinguish $P$. xanthii isolates without and with the E198A mutation, three sets of LAMP primers were designed. Set 1 (composed of primers F3, B3, FIPWT [F1c+F2_WT], and BIP [B1c+B2]) was designed to amplify only the sensitive isolates with a glutamic acid (E) at position 198. Set 2 (F3, B3, FIPMUT1 [F1c+F2_MUT1], and BIP [B1c+B2]) and set $3(\mathrm{~F} 3$, $\mathrm{B} 3$, FIPMUT2 [F1c+F2_MUT2], and BIP [B1c+B2]) were mismatched to increase the likelihood of amplifying the E198A mutation in resistant isolates specifically. Genomic DNA of the P. xanthii WT isolate SF26 and the E198A mutant isolate 2237 was used to check the specificity of the primer sets, visualizing the results via gel electrophoresis and HNB color change (Fig. 2). Set 1 was unable to discriminate between sensitive and resistant isolates and amplified both (Fig. 2). With respect to set 2 and set 3, both amplified DNA from the resistant isolate 2237, whereas DNA was not amplified from the sensitive isolate and the negative control (Fig. 2). To simplify the study,

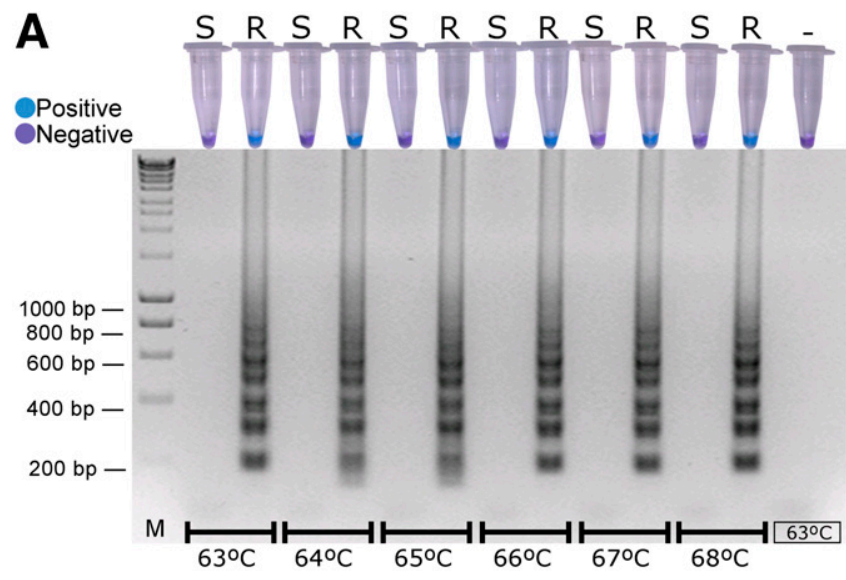

B
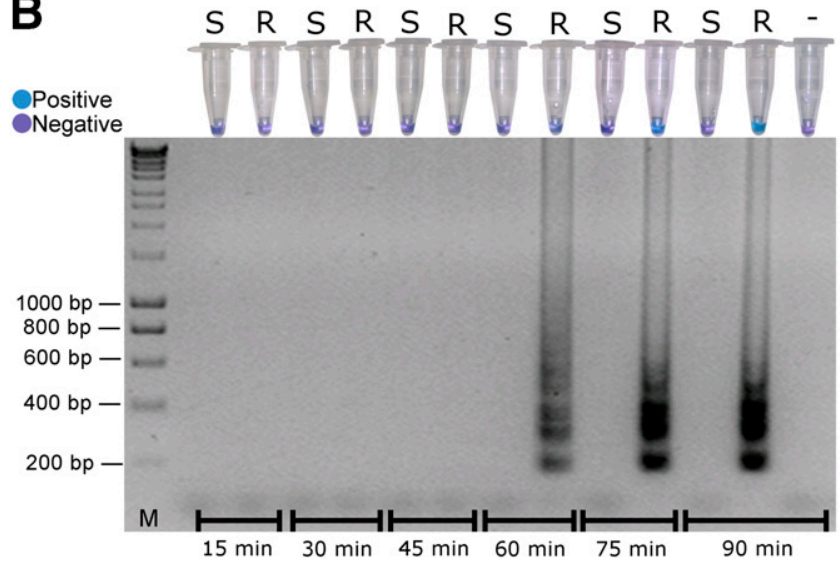

Fig. 3. Optimization of reaction conditions for primer set 2. A, The reaction temperature gradient was at $63^{\circ} \mathrm{C}, 64^{\circ} \mathrm{C}, 65^{\circ} \mathrm{C}, 66^{\circ} \mathrm{C}, 67^{\circ} \mathrm{C}$, and $68^{\circ} \mathrm{C}$. B, Reaction was set to $15,30,45,60,75$, and $90 \mathrm{~min}$. The results were visualized on the basis of hydroxynaphthol blue color change and gel electrophoresis detection. Dashes indicate the negative control without template DNA. LAMP = loop-mediated isothermal amplification, $S=$ LAMP reaction performed using DNA from the sensitive isolate SF26 as template, and R = LAMP reaction carried out using DNA from the resistant isolate 2237 . 
primer set 2 was selected for further tests to detect the E198A mutation in $P$. xanthii.

Then the optimization of temperature and time for LAMP reactions was carried out using genomic DNA from the mutant isolate 2237. The LAMP product showed a significant color change of the dye toward sky blue and a ladder-like pattern was displayed on the electrophoretic gel at all ranges of temperatures tested (Fig. 3A). To simplify the study, the final temperature chosen to optimize the reaction time was $65^{\circ} \mathrm{C}$.
Subsequently, six different times were screened. The best results were obtained at 75 and $90 \mathrm{~min}$ (Fig. 3B). Seventy-five minutes was the time chosen for the following experiments. As expected, the negative controls containing DNA from the sensitive isolate or no-template DNA did not show any HNB color change or pattern-like banding via gel electrophoresis (Fig. 3). Therefore, to detect the E198A mutation in $P$. xanthii, the optimal reaction conditions that were selected for further tests in this study were $65^{\circ} \mathrm{C}$ for $75 \mathrm{~min}$.

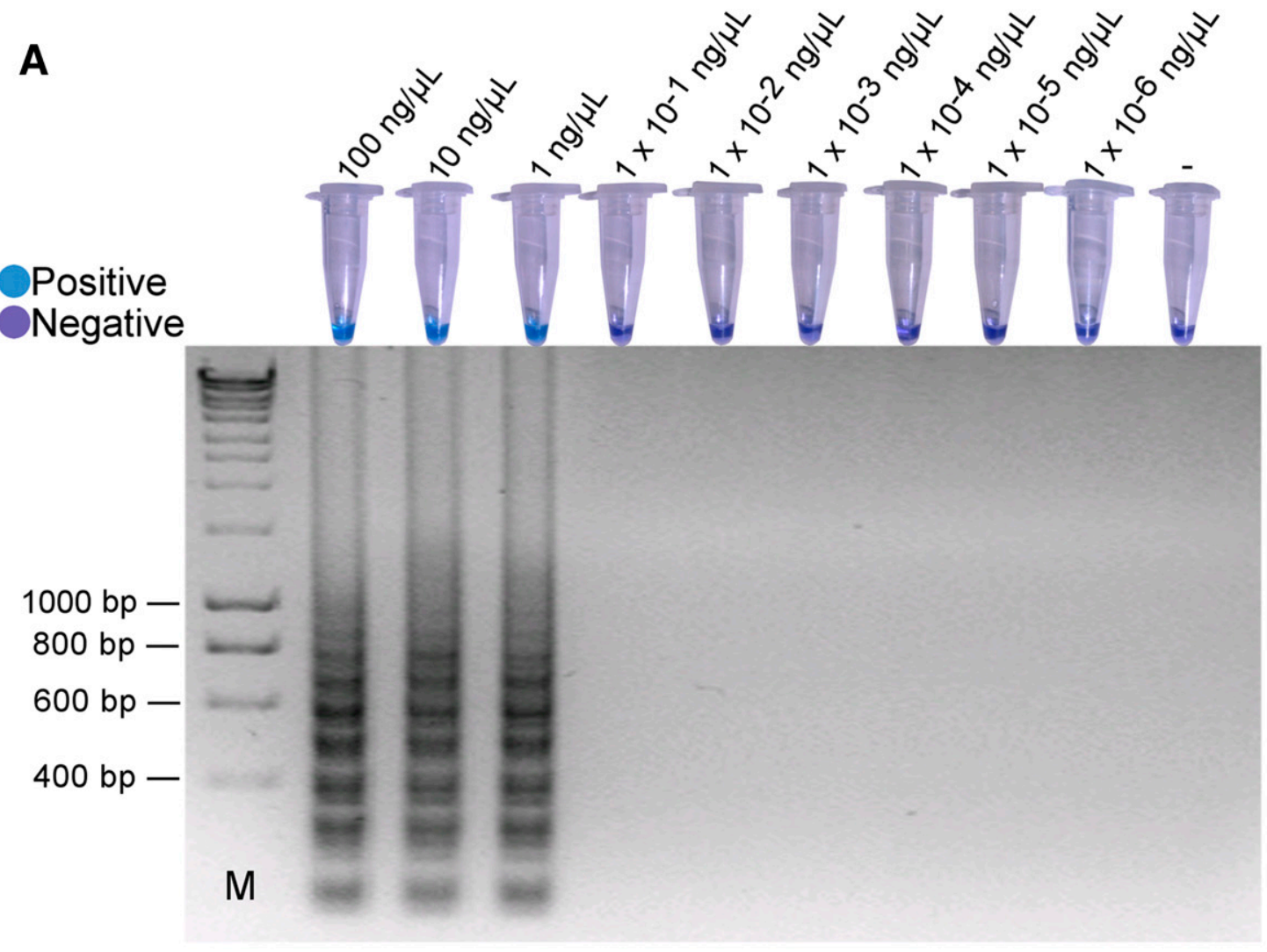

B

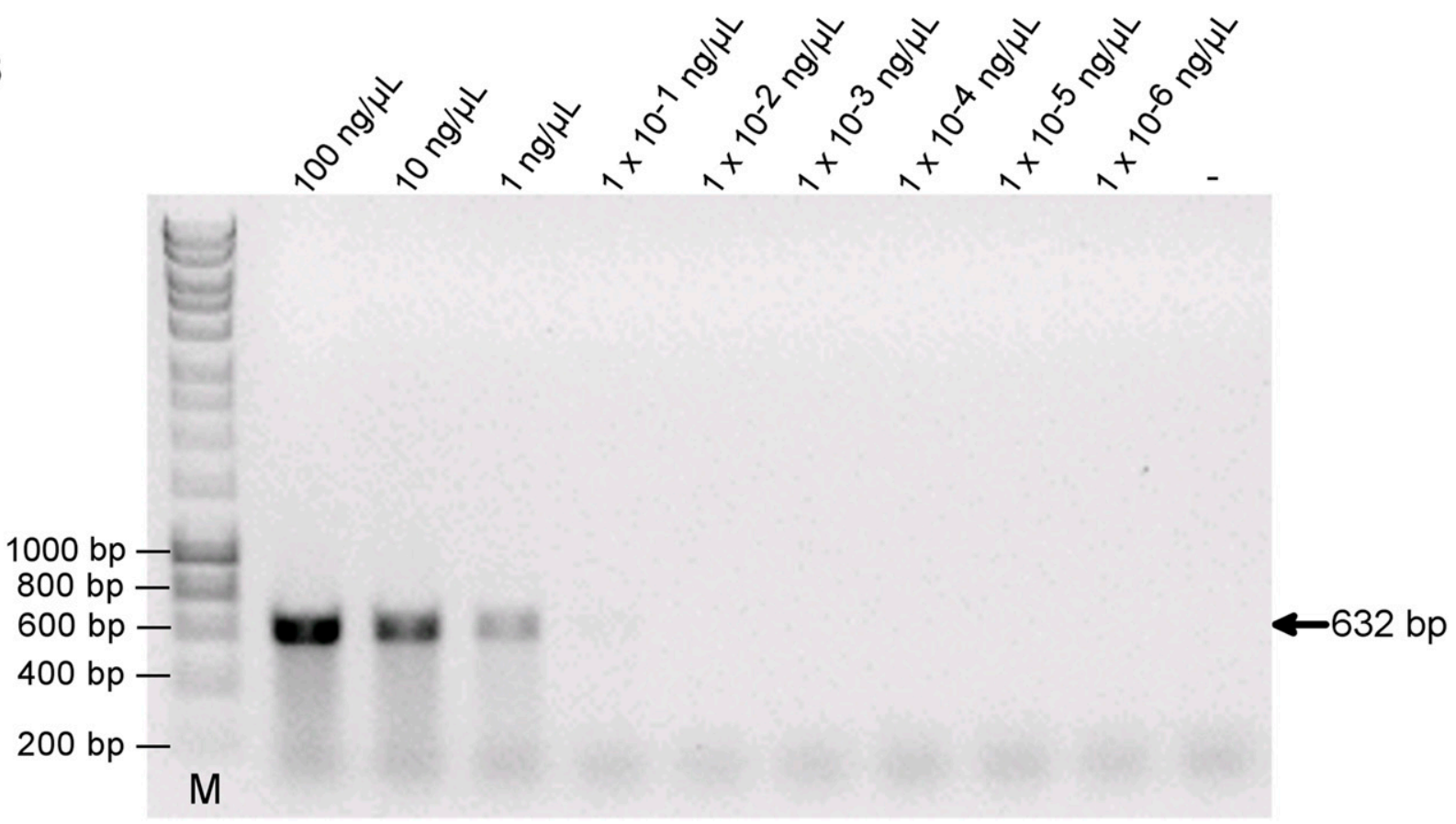

Fig. 4. Sensitivity of loop-mediated isothermal amplification (LAMP) versus polymerase chain reaction (PCR) for the detection of the E198A mutation using 10-fold serially diluted genomic DNA (from 100 to $1 \times 10^{-6} \mathrm{ng} / \mu \mathrm{l}$ ) extracted with the MasterPure Yeast DNA Purification Kit from Podosphaera xanthii isolate 2237. A, LAMP visualization on hydroxynaphthol blue and gel electrophoresis. B, PCR amplification on gel electrophoresis. Dashes indicate the negative control without template DNA. M = hyperladder $1 \mathrm{~kb}$ (Bioline). 
Confirmation of the LAMP products. The restriction enzyme LweI was used to confirm that the LAMP product corresponded with a 198-bp fragment of the $\beta$-tubulin gene and to clarify the presence or absence of the E198A mutation in this gene. In the resistant isolate, positive results were obtained for LAMP and PCR assays. The amplified products were digested with the enzyme LweI, and the digestion product revealed a three-band profile with fragments of 143, 34, and $21 \mathrm{bp}$ that were consistent with the predicted product (data not shown). Sequencing analysis also reported the amino acid alteration E198A (data not shown). For the sensitive isolate, the LAMP assay did not reveal any amplification, as was expected for primer set 2 (data not shown); the PCR digestion product revealed a two-band profile with fragments of 143 and $55 \mathrm{bp}$ (data not shown). Finally, the E198 allele was observed after sequencing analysis (data not shown).

Specificity of LAMP primers to $\boldsymbol{P}$. xanthii. Genomic DNA of several phytopathogenic fungi was included as a template for LAMP reactions together with three MBC-sensitive and three MBC-resistant $P$. xanthii isolates (including negative and positive control isolates SF26 and 2237, respectively; Table 2). Positive results on agarose gel electrophoresis and HNB color change from violet to sky blue were only detected with the $P$. xanthii-resistant isolates 2237, 24794, and 61485, which are known to carry the E198A amino acid change in $\beta$-tubulin (Table 2).

Repeatability of LAMP using $P$. xanthii isolates from different countries. The reliability and robustness of the LAMP assay was tested with $42 P$. xanthii isolates from different cucurbit crops and countries. As expected, only the MBC-resistant isolates, which were able to grow at the discriminatory dose of $675 \mu \mathrm{g} / \mathrm{ml}$ of thiophanate-methyl on leaf-disc bioassays, showed a positive LAMP result (Table 3), However, the LAMP reaction was negative in all of the sensitive isolates (Table 3), meaning that these isolates were unable to grow at the discriminatory dose tested. The sequencing analysis of 16 randomly selected isolates revealed the

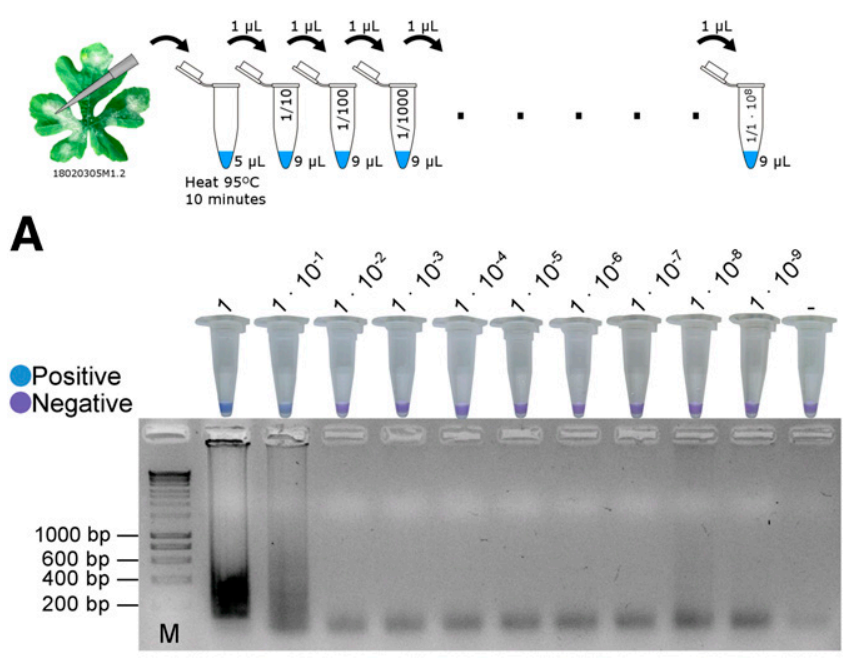

B

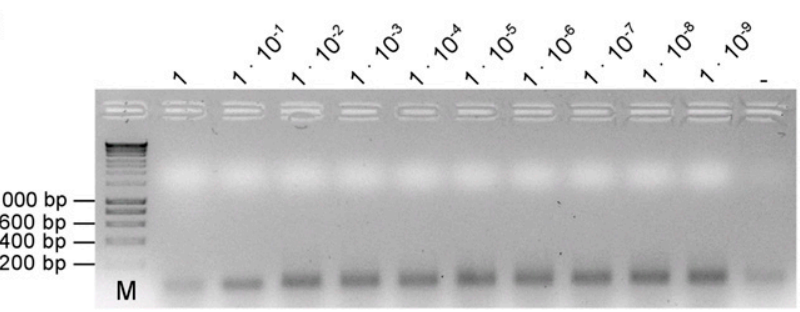

Fig. 5. Sensitivity of loop-mediated isothermal amplification (LAMP) versus polymerase chain reaction (PCR) for the detection of the E198A amino acid change using 10 -fold serially diluted genomic DNA obtained by heating a solution of sterile distilled water with fungal biomass (bulk conidial mass 18020305M1.2) collected directly from powdery mildew-infected material. A, LAMP visualization via hydroxynaphthol blue and gel electrophoresis. B, PCR amplification visualized on gel electrophoresis. Dashes indicate the negative control without template DNA. $\mathrm{M}=$ hyperladder $1 \mathrm{~kb}$ (Bioline) presence of the E198A mutation only in the resistant isolates (Table 3).

Application of LAMP for monitoring MBC-resistant field isolates of $\boldsymbol{P}$. xanthii. To apply the LAMP assay to monitor $P$. xanthiiresistant isolates in the field, total DNA was extracted by heating a solution of sterile distilled water with fungal biomass collected directly from powdery mildew-infected material (bulk conidial mass) and from single-spore isolates obtained from the infected material. The lysate was added to the LAMP mixture as a template. The results from the infected plant material collected in Granada showed that $33 \%$ of the bulk conidial isolates and $40 \%$ of the single-spore isolates, respectively, were resistant to thiophanate-methyl on leaf-disc assays and had positive LAMP reactions based on HNB visualization and gel electrophoresis results (Table 4). In relation to the samples collected from Almería, 100\% of the samples tested (bulk conidial and single-spore isolates) were $\mathrm{MBC}$ resistant in the in vitro fungicide sensitivity test and LAMP assay (Table 4). The LAMP assay took $1 \mathrm{~h}$ and $15 \mathrm{~min}$ to obtain results from field samples, considerably reducing the time for diagnosis.

Sensitivity of LAMP compared with conventional PCR. For the sensitivity test, 10-fold serially diluted genomic DNA (from 100 to $\left.1 \times 10^{-6} \mathrm{ng} / \mu \mathrm{l}\right)$ extracted in the laboratory and 10-fold serially diluted DNA extracted directly from naturally infected field samples were used as a template for LAMP and PCRs. The amplification products were detected by gel electrophoresis for LAMP and PCRs and for HNB color change for LAMP. When genomic DNA extracted using a conventional extraction method was used as a template, the results obtained were very similar, with a detection limit of $1 \mathrm{ng} / \mu \mathrm{l}$ for LAMP and PCR (Fig. 4); however, when DNA was extracted in 5 min directly from the infected material, the sensitivity of LAMP was 100-fold higher than PCR (Fig. 5).

\section{Discussion}

To select the most proper fungicides and prevent dramatic control failures, the development of a rapid, economical, and highthroughput technique is necessary for detecting fungicide-resistant populations of $P$. xanthii. Detection of MBC-resistant isolates of the powdery mildew pathogen in the field has been based on conventional methods through leaf-disc bioassays, determining the $50 \%$ effective concentration $\left(\mathrm{EC}_{50}\right)$ value and discriminatory doses to be able to distinguish sensitive from resistant isolates; however, these methods must be conducted for weeks before results are available (Bellón-Gómez et al. 2015; Colcol and Baudoin 2016; Pearson and Taschenberg 1980; Sedláková and Lebeda 2008; Vargas 1973).

In the present study, a LAMP assay was developed to detect the E198A amino acid change in $\beta$-tubulin, the only mutation that confers resistance to MBC fungicides in the Spanish P. xanthii population. Other studies have developed LAMP assays for the quick detection of point mutations involved in MBC resistance in different pathogens, such as the amino acid changes E198A/K/V and F200Y in $B$. cinerea (Duan et al. 2018a, 2018b); F167Y, E198Q, and F200Y in F. asiaticum (Duan et al. 2016a; Komura et al. 2018); and E198A and F200Y in Sclerotinia sclerotiorum (Duan et al. 2015, 2016b). To our knowledge, this is the first time that a LAMP assay was used for the detection of fungicide resistance in a biotrophic fungus such as cucurbit powdery mildew.

The LAMP assay developed in this study is an alternative test to distinguish $P$. xanthii MBC-sensitive isolates from MBC-resistant isolates in the laboratory and in cucurbit fields. Until now, a diagnostic system to molecularly detect MBC resistance in $P$. xanthii was developed using an allele-specific PCR assay (Vela-Corcía et al. 2014); however, with this technique, DNA of suitable quality and sufficient quantity was necessary, involving approximately five zucchini cotyledons infected with single-spore isolates of the powdery mildew pathogen, protocols that are time- and labor-consuming and have many equipment requirements. In addition, after approximately $1.5 \mathrm{~h}$ of a PCR, the amplification product must be analyzed by electrophoresis on agarose gels (Vela-Corcía et al. 2014), preventing this test from being carried out outside the laboratory. With the LAMP assay developed in this study, sample preparation can be kept to a 
minimum; with only a 5-min incubation at $95^{\circ} \mathrm{C}$, a small amount of fungal biomass covering the lower end of a pipette tip is enough to obtain suitable DNA that can be used directly in LAMP reactions. In addition, the reaction can be performed at one continuous temperature in a heated block, obviating the need for thermal cycling equipment, and signal detection is possible using the naked eye. The procedure is simple and allows an on-site assay that, together with portable devices now available on the market, will provide a yes/ no result directly in the field in approximately $1 \mathrm{~h}$, including the time required for DNA extraction.

Compared with conventional PCR, the sensitivity of the LAMP assay developed in this study for on-site detection of MBC-resistant $P$. xanthii is 100 -fold higher than that of PCR. The majority of the studies performed to compare the sensitivity of LAMP to conventional PCR have been carried out by cloning the target gene into vectors and using the recombinant plasmid extracted from positive clones, after serial dilution, as a template. These studies have reported LAMP sensitivity 100-, 1,000-, and even 10,000-fold higher than that of PCR (Duan et al. 2015, 2016a, 2018a), and only one study has shown opposite results (Fan et al. 2018). Regarding LAMP sensitivity studies using genomic DNA extracted directly from field samples, Hu et al. (2017) reported a limit of $0.01 \mathrm{ng} / \mu \mathrm{l}$ of DNA for the detection of the G143A mutation in the cytb gene; unfortunately, the authors did not compare the sensitivity of LAMP with that of PCR (Hu et al. 2017). In our study, the sensitivity of LAMP was similar to PCR, with a detection limit of $1 \mathrm{ng} / \mu \mathrm{l}$ when serially diluted genomic DNA, extracted with a kit commonly used in the laboratory, was added as a template. However, the sensitivity of LAMP was 100-fold higher than that of the PCR when the DNA used as a template was extracted in 5 min directly from powdery mildew-infected material. One way or another, the sensitivity obtained in our study was enough for the detection of the E198A mutation in the cucurbit powdery mildew pathogen from several countries (Austria, France, Greece, Italy, and Spain), and the results obtained were comparable with the conventional fungicide sensitivity tests carried out using leaf-disc bioassays, demonstrating potential for the use of LAMP throughout the world.

In conclusion, the LAMP method developed in this study in combination with $\mathrm{HNB}$ is a simple, quick, and reliable method for the detection of MBC-resistant isolates of $P$. xanthii carrying the E198A mutation and could be a useful tool for future monitoring and management of $P$. xanthii resistance both in the laboratory and in the field. Rapid determination of farm-specific resistance profiles in cucurbit fields will permit growers to identify failures in their spray program and tailor spray sequences to farm-specific needs.

\section{Acknowledgments}

This paper is dedicated to Dr. Juan Antonio Torés (1952-2018).

\section{Literature Cited}

Agrios, G. 2005. Plant Pathology, 5th ed. Elsevier, Amsterdam, The Netherlands. Álvarez, B., and Torés, J. A. 1997. Cultivo in vitro de Sphaerotheca fuliginea (Schlecht. ex. Fr.), efecto de diferentes fuentes de carbono sobre su desarrollo. Bol. Sanid. Veg., Plagas 23:283-288.

Bellón-Gómez, D., Vela-Corcía, D., Pérez-García, A., and Torés, J. A. 2015. Sensitivity of Podosphaera xanthii populations to anti-powdery-mildew fungicides in Spain. Pest Manag. Sci. 71:1407-1413.

Chi, M. H., Park, S. Y., and Lee, Y. H. 2009. A quick and safe method for fungal DNA extraction. Plant Pathol. J. 25:108-111.

Colcol, J. F., and Baudoin, A. B. 2016. Sensitivity of Erysiphe necator and Plasmopara viticola in Virginia to QoI fungicides, boscalid, quinoxyfen, thiophanate methyl, and mefenoxam. Plant Dis. 100:337-344.

Duan, Y. B., Yang, Y., Li, M. X., Li, T., Fraaije, B. A., and Zhou, M. G. 2018a. Development and application of a simple, rapid and sensitive method for detecting moderately carbendazim-resistant isolates in Botrytis cinerea. Ann. Appl. Biol. 172:355-365.

Duan, Y. B., Yang, Y., Li, T., Zhao, D., Cao, J., Shi, Y., Wang, J., and Zhou, M. G. 2016a. Development of a rapid and high-throughput molecular method for detecting the F200Y mutant genotype in benzimidazole-resistant isolates of Fusarium asiaticum. Pest Manag. Sci. 72:2128-2135.

Duan, Y. B., Yang, Y., Wang, J. X., Chen, C. J., Steinberg, G., Fraaije, B. A., and Zhou, M. G. 2018b. Simultaneous detection of multiple benzimidazole-resistant $\beta$-tubulin variants of Botrytis cinerea using loop-mediated isothermal amplification. Plant Dis. 102:2016-2024.

Duan, Y. B., Yang, Y., Wang, J. X., Liu, C. C., He, L. L., and Zhou, M. G. 2015. Development and application of loop-mediated isothermal amplification for detecting the highly benzimidazole-resistant isolates in Sclerotinia sclerotiorum. Sci. Rep. 5:17278.

Duan, Y. B., Yang, Y., Wang, Y., Pan, X., Wu, J., Cai, Y., Li, T., Zhao, D., Wang, J., and Zhou, M. G. 2016b. Loop-mediated isothermal amplification for the rapid detection of the $\mathrm{F} 200 \mathrm{Y}$ mutant genotype of carbendazim-resistant isolates of Sclerotinia sclerotiorum. Plant Dis. 100:976-983.

Duan, Y. B., Zhang, X., Ge, C., Wang, Y., Cao, J., Jia, X., Wang, J., and Zhou, M. 2014. Development and application of loop-mediated isothermal amplification for detection of the F167Y mutation of carbendazim-resistant isolates in Fusarium graminearum. Sci. Rep. 4:1-8.

Fan, F., Yin, W. X., Li, G. Q., Lin, Y., and Luo, C. X. 2018. Development of a LAMP method for detecting SDHI fungicide resistance in Botrytis cinerea. Plant Dis. 102:1612-1618.

Fernández-Ortuño, D., Grabke, A., Li, X., and Schnabel, G. 2015. Independent emergence of resistance to seven chemical classes of fungicides in Botrytis cinerea. Phytopathology 105:424-432.

Fernández-Ortuño, D., Pérez-García, A., López-Ruiz, F., Romero, D., De Vicente, A., and Torés, J. A. 2006. Occurrence and distribution of resistance to QoI fungicides in populations of Podosphaera fusca in south central Spain. Eur. J. Plant Pathol. 115:215-222.

Fernández-Ortuño, D., Torés, J. A., de Vicente, A., and Pérez-García, A. 2008. Field resistance to QoI fungicides in Podosphaera fusca is not supported by typical mutations in the mitochondrial cytochrome $b$ gene. Pest Manag. Sci. 64:694-702.

Fungicide Resistance Action Committee. 2019. FRAC Code List 2019: Fungal control agents sorted by cross resistance pattern and mode of action. http://www.frac.info

Hollomon, D. W., and Wheeler, I. 2002. Controlling powdery mildews with chemistry. Pages 249-255 in: The Powdery Mildews: A Comprehensive Treatise. American Phytopathological Society Press, St. Paul, MN.

Hu, X. R., Dai, D. J., Wang, H. D., and Zhang, C. Q. 2017. Rapid on-site evaluation of the development of resistance to quinone outside inhibitors in Botrytis inereal. Sci. Rep. 7:13861.

Ishii, H., Fraaije, B. A., Sugiyama, T., Noguchi, K., Nishimura, K., Takeda, T., Amano, T., and Hollomon, D. W. 2001. Occurrence and molecular characterization of strobilurin resistance in cucumber powdery mildew and downy mildew. Phytopathology 91:1166-1171.

Komura, R., Kawakami, T., Nakajima, K., Suzuki, H., and Nakashima, C. 2018. Simultaneous detection of benzimidazole-resistant strains of Fusarium head blight using the loop-mediated isothermal amplification-fluorescent loop primer method. J. Gen. Plant Pathol. 84:247-253.

Leonar, P., and Gianessi, N. R. 2005. The Value of Fungicides in U.S. Crop Production. CropLife Foundation, Washington, DC.

López-Ruiz, F., Pérez-García, A., Fernández-Ortuño, D., Romero, D., García, E., de Vicente, A., Brown, J. K. M., and Torés, J. A. 2010. Sensitivities to DMI fungicides in populations of Podosphaera fusca in south central Spain. Pest Manag. Sci. 66:801-808.

Luo, Q. Q., Xu, J. Q., Hou, Y. P., Chen, C. J., Wang, J. X., and Zhou, M. G. 2009. PIRA-PCR for detection of Fusarium graminearum genotypes with moderate resistance to carbendazim. Plant Pathol. 58:882-887.

Ma, Z., and Michailides, T. J. 2004. An allele-specific PCR assay for detecting azoxystrobin-resistant Alternaria isolates from pistachio in California. $\mathrm{J}$. Phytopathol. 152:118-121.

Ma, Z., and Michailides, T. J. 2005. Advances in understanding molecular mechanisms of fungicide resistance and molecular detection of resistant genotypes in phytopathogenic fungi. Crop Prot. 24:853-863.

Ma, Z., Yoshimura, M., Holtz, B., and Michailides, T. 2005. Characterization and PCR-based detection of benzimidazole-resistant isolates of Monilinia laxa in California. Pest Manag. Sci. 61:449-457.

McGrath, M. T. 2001. Fungicide resistance in cucurbit powdery mildew: Experiences and challenges. Plant Dis. 85:236-245.

Ministerio de Agricultura y Pesca y Alimentación. 2015. Anuario de Estadística https://www.mapa.gob.es/es/estadistica/temas/publicaciones/anuario-deestadistica $/ 2017 /$ default.aspx ?parte $=3 \&$ capitulo $=13 \&$ grupo $=6 \&$ seccion $=20$

Niessen, L. 2014. Current state and future perspectives of loop-mediated isothermal amplification (LAMP)-based diagnosis of filamentous fungi and yeasts. Appl. Microbiol. Biotechnol. 99:553-574.

Pearson, R. C., and Taschenberg, E. F. 1980. Benomyl-resistant strains of Uncinula necator on grapes. Plant Dis. 64:677-680.

Pérez-García, A., Mingorance, E., Rivera, M. E., del Pino, D., Romero, D., Torés, J. A., and de Vicente, A. 2006. Long-term preservation of Podosphaera xanthii using silica gel. J. Phytopathol. 154:190-192.

Pérez-García, A., Romero, D., Fernández-Ortuño, D., López-Ruiz, F., De Vicente, A., and Torés, J. A. 2009. The powdery mildew fungus Podosphaera fusca (synonym Podosphaera xanthii), a constant threat to cucurbits. Mol. Plant Pathol. 10:153-160.

Rur, M., Rämert, B., Hökeberg, M., Vetukuri, R. R., Grenville-Briggs, L., and Liljeroth, E. 2018. Screening of alternative products for integrated pest management of cucurbit powdery mildew in Sweden. Eur. J. Plant Pathol. 150:127-138. 
Schroeder, W. T., and Provvidenti, R. 1969. Resistance to benomyl in powdery mildew of cucurbits. Plant Dis. Rep. 53:271-275.

Sedláková, B., and Lebeda, A. 2008. Fungicide resistance in Czech populations of cucurbit powdery mildews. Phytoparasitica 36:272-289.

Sitterly, W. R. 1978. Powdery mildew of cucurbits. Pages 359-377 in: Powdery Mildews. D. M. Spencer, ed. Academic Press, New York.
Vargas, J. M. 1973. A benzimidazole resistant strain of Erysiphe graminis. Phytopathology 63:1366-1368.

Vela-Corcía, D., Bellón-Gómez, D., López-Ruiz, F., Torés, J. A., and PérezGarcía, A. 2014. The Podosphaera fusca TUB2 gene, a molecular "Swiss Army knife" with multiple applications in powdery mildew research. Fungal Biol. 118:228-241. 